\title{
RADIOCARBON ACTIVITY VARIATION IN DATED TREE RINGS GROWN IN MACKENZIE DELTA
}

\author{
C Y FAN \\ Department of Physics, University of Arizona, Tucson \\ CHEN TIE-MEI, YUN SI-XUN \\ Radiocarbon Laboratory, Archaeological Section, History Department \\ Peking University, Beijing, China \\ and \\ DAI KAI-MEI \\ Department of Physics, Nanjing University, Nanjing, China
}

\begin{abstract}
We measured the $\Delta^{14} \mathrm{C}$ values in 57 rings (from AD 1824 to 1880) of a white spruce grown in Mackenzie Delta $\left(68^{\circ} \mathrm{N}, 130^{\circ} \mathrm{W}\right)$, as part of our continuing study of the $\Delta^{14} \mathrm{C}$ variation related to solar activities. The values exhibit a $10 \%$ fluctuation with an 11 -year periodicity anti-correlated with the solar activity cycle. We also measured the $\Delta^{14} C$ values in 6 rings (from AD 1940 to 1945). The abnormally high value in the 1943 ring may be due to two large solar flares occurring in 1942.
\end{abstract}

\section{INTRODUCTION}

${ }^{14} \mathrm{C}$ nuclei in the atmosphere are produced by cosmic-ray-generated neutrons in ${ }^{14} \mathrm{~N}(\mathrm{n}, \mathrm{p}){ }^{14} \mathrm{C}$ reaction. After production, these nuclei react rapidly with ambient atmosphere to become ${ }^{14} \mathrm{CO}_{2}$ molecules. The concentration of the molecules is mainly determined by their production rate and transfer rate, first to the troposphere from the stratosphere where most of them are produced, and then from the troposphere to the deep-sea sink reservoir. Since cosmic ray intensity is modulated by interplanetary magnetic fields, the strength of which depends on solar activity, it is expected that the concentration is anti-correlated with sunspot numbers. While longterm change in $\Delta^{14} \mathrm{C}$ in tree samples, which reflects variation of atmospheric ${ }^{14} \mathrm{C}$ concentration, has been studied by many investigators and the correlation established beyond any doubt (eg, Stuiver \& Quay, 1980, and references therein), the magnitude of the expected 11-year variation remains questionable (Damon, Long \& Wallick, 1973; Povinec, 1983).

There was some indication that $\Delta^{14} \mathrm{C}$ values in grains and trees grown at high latitudes show 11 -year periodicity (Baxter \& Farmer, 1973; Povinec, 1983). To study the possible latitudinal effect, we looked for trees from the most northerly region and fortunately obtained two sections of white spruce grown near Campbell River in Mackenzie Delta, Canada $\left(68^{\circ} \mathrm{N}\right.$, $\left.130^{\circ} \mathrm{W}\right)$. One of the sections contains rings from AD 1510 to 1972 . Initial measurements of 21 samples, covering the period AD 1881 to 1925 indicated a $10 \%$ fluctuation in $\Delta^{14}$ values anti-correlated with sunspot numbers (Fan et al, 1983). In this paper we shall report $\Delta^{14} \mathrm{C}$ in rings from $\mathrm{AD} 1824$ to 1880 . We also measured the $\Delta^{14} \mathrm{C}$ in $1940-1945$ rings, looking for the signature of $\Delta^{14} \mathrm{C}$ increase, due to two large solar flares that occurred in 1942 and were reported by Forbush (1946). 


\section{EXPERIMENTAL METHOD}

The measurements were made by two institutions; the 1824 to 1880 rings were measured at the Department of History, Peking University; the 1940 to 1945 rings were measured at the Department of Physics, Nanjing University. The measuring systems used were similar, a liquid scintillatorphotomultiplier tube device. Two photomultiplier tubes were connected in coincidence to count ${ }^{14} \mathrm{C}$ decay electrons with a pulse height discrimination to reduce cross-talks between the two tubes. There was however, a slight difference between the two systems. At Peking University, 5 to $10 \mathrm{~cm}$ of lead were used to reduce cosmic-ray induced background; at Nanjing University, in addition to a lead shield, a plastic scintillator-photomultiplier system was used as an anti-coincidence shield. The result of the addition was a reduction of background from $6 \mathrm{cpm}$ to $2 \mathrm{cpm}$. An overall precision of both systems was ca $4 \%$, including a purely statistical uncertainty of ca $3 \%$.

For each measurement, ca $10 \mathrm{~g}$ of wood were needed. Because of the narrow rings, except the 1928 ring, we had to combine 2, and sometimes 3 rings to obtain a sufficient specimen for one measurement. After being treated with the routine $\mathrm{HCl}-\mathrm{NaOH}-\mathrm{HCl}$ procedure to remove resin, the samples were converted to $\mathrm{CO}_{2}$ and then to benzene. For one measurement, $5 \mathrm{cc}$ of synthesized benzene was used. The net count rate for a modern sample was $39 \mathrm{cpm}$. We measured ${ }^{13} \mathrm{C} /{ }^{12} \mathrm{C}$ for fractionation correction for each sample.

\section{EXPERIMENTAL RESULTS}

\section{$\Delta^{14} \mathrm{C}$ in $A D$ 1824-1880 Rings}

The experimental results are expressed as $\Delta^{14} \mathrm{C}$ values which are the relative deviations of the measured ${ }^{14} \mathrm{C}$ activities from the standard oxalic acid activity of the US National Bureau of Standards, corrected for ages and isotopic fractionations. For samples prior to AD 1880 , the correction for the Suess effect was not needed.

Table 1 lists the 26 tree-ring samples and their corresponding $\delta^{13} \mathrm{C}$ and $\Delta^{14} \mathrm{C}$ values. The data points, including 5 previously published values, are plotted in the bottom panel of Figure 1 , along with other published $\Delta^{14} \mathrm{C}$ values for comparison. In the upper panel we plotted the sunspot numbers with ordinates inverted to show the anti-correlation with solar activity. The coefficient for the correlation, with the $\Delta^{14} \mathrm{C}$ values delayed by 4 years, is -0.38 . However, if the AD 1823-1833 cycle is not included for the analysis, the correlation coefficient becomes -0.48 . This is due to the fact that there are three $\Delta^{14} \mathrm{C}$ values in that cycle, namely AD 1826-1830, which appear to be abnormally low. We noted that the $1928 \mathrm{ring}$ and its two near neighbors are exceptionally wide. We are wondering about the possibility that the low values are indicative of an abnormal environment in these years.

In estimating the significance of the correlation, we are hampered by two unknown factors: 1) the sunspot number and cosmic ray intensity are only loosely correlated so that the functional relationship is not known; 2) it is likely that some of the $\Delta^{14} \mathrm{C}$ fluctuations are due to other causes such as 
TABLE 1

Radiocarbon content in tree rings

\begin{tabular}{|c|c|c|c|}
\hline $\begin{array}{c}\text { Sample } \\
\text { no. }\end{array}$ & $\begin{array}{c}\text { Tree-ring } \\
\text { dates }\end{array}$ & $\begin{array}{c}\delta^{13} \mathrm{C} \\
\% 00\end{array}$ & $\begin{array}{c}{ }^{14} \mathrm{C}( \pm 4 \% 0) \\
\% 00\end{array}$ \\
\hline $\begin{array}{r}82307 \\
82308 \\
82309 \\
82310 \\
82311 \\
82312 \\
83303 \\
83301 \\
83302 \\
83304 \\
83306 \\
83305 \\
\text { BK } 85206 \\
\text { BK } 85207 \\
\text { BK } 85201 \\
\text { BK } 85202 \\
\text { BK } 85203 \\
\text { BK } 85204 \\
\text { BK } 85205\end{array}$ & $\begin{array}{c}1879-1880 \\
1877-1878 \\
1875-1876 \\
1872-1874 \\
1870-1871 \\
1866-1867 \\
1864-1865 \\
1862-1863 \\
1860-1861 \\
1858-1859 \\
1856-1857 \\
1854-1855 \\
1852-1853 \\
1850-1851 \\
1847-1849 \\
1845-1846 \\
1842-1844 \\
1840-1841 \\
1838-1839 \\
1835-1837 \\
1833-1834 \\
1831-1832 \\
1829-1830 \\
1828 \\
1826-1827 \\
1824-1825\end{array}$ & $\begin{array}{l}-25.91 \\
-25.84 \\
-26.23 \\
-26.21 \\
-26.53 \\
-25.75 \\
-26.22 \\
-25.82 \\
-25.74 \\
-25.96 \\
-26.42 \\
-26.36 \\
-25.80 \\
-26.47 \\
-25.95 \\
-25.86 \\
-25.95 \\
-25.88 \\
-25.72 \\
(-25.80)^{*} \\
(-25.80)^{*} \\
(-25.80)^{*} \\
(-25.80)^{*} \\
(-25.80)^{*} \\
(-25.80)^{*} \\
(-25.80)^{*}\end{array}$ & $\begin{array}{l}-11.1 \\
-13.5 \\
-20.3 \\
-14.1 \\
-\quad 2.3 \\
-1.3 \\
-18.7 \\
+3.5 \\
+5.1 \\
-0.3 \\
-12.0 \\
-8.2 \\
-6.8 \\
-5.0 \\
+1.4 \\
+4.0 \\
-5.2 \\
-2.7 \\
+0.2 \\
+4.9 \\
+0.4 \\
+3.6 \\
-5.5 \\
-12.2 \\
-4.8 \\
+8.4\end{array}$ \\
\hline
\end{tabular}

* Estimated

environmental conditions and solar events. However, if we assume that sunspot number and $\Delta^{14} \mathrm{C}$ were correlated linearly and other causes were unimportant, then the slope of the regression line is $-0.11 \pm 0.02$.

\section{$\Delta^{14} C$ in $A D$ 1940-1945 Rings}

In their study of the magnitude of the 11 -year ${ }^{14} \mathrm{C}$ cycle, Damon, Long \& Wallick (1973) found that the ${ }^{14} \mathrm{C}$ content in the 1943 ring of their Arizona tree sample $\left(32^{\circ} \mathrm{N}, 112^{\circ} \mathrm{W}\right)$ is exceptionally high. They attributed this high activity to the ${ }^{14} \mathrm{C}$ production by two large solar flares, on February 28 and March 7, 1942, detected by Forbush (1946). A similar increase was also found by Burchuladze et al (1980) in their wine sample. Since our tree section was from Mackenzie Delta, only ca $10^{\circ}$ from the north geomagnetic pole, we expect to observe a larger ${ }^{14} \mathrm{C}$ activity increase in the tree ring than in the sample of Damon, Long and Willick.

In Figure 2 we plotted $6 \Delta^{14} \mathrm{C}$ values in the AD 1940-1945 rings, together with the measurements by Damon, Long and Wallick, by Burchuladze et al (1980), and by Stuiver and Quay (1980) in the period from AD 1940 to 1954 . The high $\Delta^{14} \mathrm{C}$ values in the Mackenzie wood, as compared with that of the other three measurements can be explained by the fact that, in the near Arctic circle, the air is less contaminated by fossil fuel burning. Disregarding the difference in the general $\Delta^{14} \mathrm{C}$ level, the increase in $\Delta^{14} \mathrm{C}$ in the 1943 ring of the Mackenzie wood agrees remarkably well with that in 

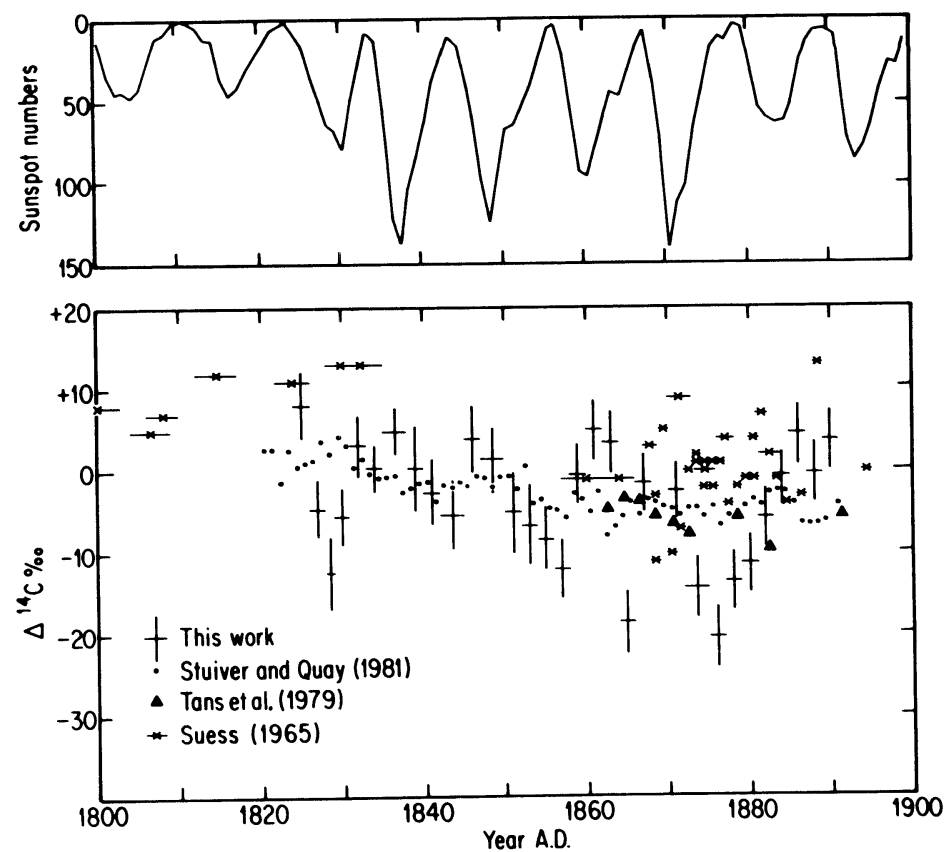

Fig 1. Upper panel: Sunspot numbers plotted with ordinates inverted. Lower panel: $\Delta^{14}$ in the AD 1824-1890 rings of a white spruce from Mackenzie Delta, Canada $\left(60^{\circ} \mathrm{N}, 130^{\circ} \mathrm{W}\right)$. For comparison, the measurements by Suess, by Tans et al, and by Stuiver and Quay are also plotted.

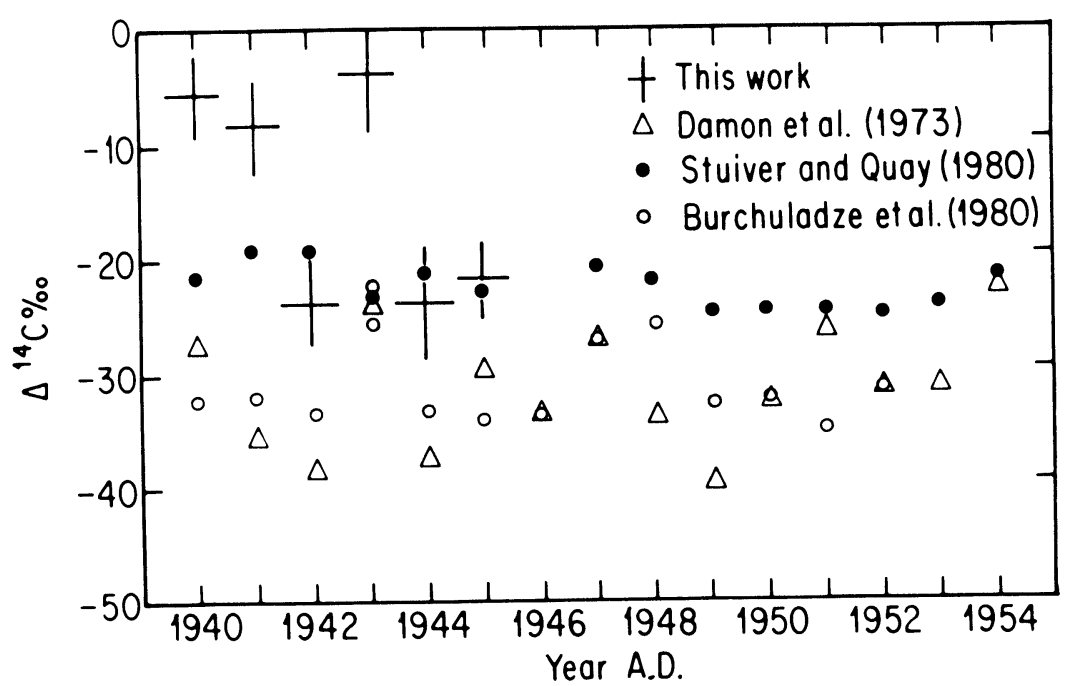

Fig 2. $\Delta^{14} \mathrm{C}$ in the AD $1940-1945$ rings of a white spruce from Mackenzie Delta, Canada, showing the abnormally high $\Delta^{14} \mathrm{C}$ value in the 1943 ring. 
the Arizona wood and Georgian grain. The puzzling fact is that the Washington State sample of Stuiver and Quay does not show any sign of increase.

\section{DISCUSSION AND CONCLUSION}

The variation of $\Delta^{14} \mathrm{C}$ values in the $\mathrm{AD}$ 1824-1880 rings of the Mackenzie Delta spruce shows an 11 -year periodicity, anti-correlated with sunspot numbers. The magnitude of the variation is ca $10 \%$. These results are in general agreement with those found in the 1881-1925 rings. To explain this magnitude, which is 3 to 4 times that found in tree samples from lower latitudes, we suggested that it is due to the combination of three factors: 1) the increase in the ${ }^{14} \mathrm{C}$ production rate from solar maximum to solar minimum is $33 \%$ over the $60^{\circ}-90^{\circ}$ geomagnetic latitude range as compared to $11 \%$ over the $0^{\circ}-60^{\circ}$ range; 2 ) the time scale of the transport of $\mathrm{CO}_{2}$ molecule across latitudes in the stratosphere is much longer than that from the stratosphere to the troposphere; 3 ) in the $60^{\circ}-90^{\circ} \mathrm{N}$ geographic latitude region, the ocean surface area is only ca $30 \%$ of that of the land mass. Consequently, there is always a meridional gradient in atmospheric ${ }^{14} \mathrm{C}$ concentration, the variation of which follows that in the stratosphere but with a damping in amplitude and delay in time. We feel that this explanation still holds, although the third factor may not be essential as we thought originally.

In a separate paper presented at this conference (Dai \& Fan, 1985), the measurement of the ${ }^{14} \mathrm{C}$ contents in 1962-1968 tree rings from three different latitudes are reported. We found that the concentration gradient of bomb-produced ${ }^{14} \mathrm{C}$ lasted for ca 6 years. This result may be taken as an experimental verification of the existence of a steady meridional gradient in ${ }^{14} \mathrm{C}$ concentration for several years, should there be a ${ }^{14} \mathrm{C}$ atom excess in the polar region, even for a short duration.

The abnormally high $\Delta^{14} \mathrm{C}$ in 1943 found in three laboratories is very interesting. If it is indeed due to the two solar flares in 1942, then it is the first time that solar proton-produced ${ }^{14} \mathrm{C}$ nuclei were found in tree rings. The magnitude of the flares can be estimated as follows:

From September to November of 1961 and then from August to December of 1962, series of high altitude nuclear bomb tests of the USSR added ca $3.5 \times 10^{28}{ }^{14} \mathrm{C}$ atoms to the atmosphere, mostly in the stratosphere (Fairhall \& Young, 1970). This addition of ${ }^{14} \mathrm{C}$ atoms is registered in the Mackenzie Delta tree as $\Delta^{14} \mathrm{C}$ increases of $640 \% 0$ and $710 \% 0$ in the 1963 and 1964 rings, respectively (Dai \& Fan, 1986). These values provide us a calibration for the tree-ring response to a delta-function-like input of ${ }^{14} \mathrm{C}$ atoms into the stratosphere in a high latitude region. It is certainly the case for ${ }^{14} \mathrm{C}$ atoms produced by solar flare protons.

The $\Delta^{14} \mathrm{C}$ in the 1943 rings is ca $20 \%$ above that in the 1942 and 1944 rings. Take $680 \%$ as the average increase of $\Delta^{14} \mathrm{C}$ due to the injection of $3.5 \times 10^{28}{ }^{14} \mathrm{C}$ atoms by the bomb tests, then the number of ${ }^{14} \mathrm{C}$ atoms produced by the two solar flare events in February and March, 1942 is ca $10^{27}$. It is about the magnitude as that by the solar event on February 23, 1956 (Lingenfelter \& Ramaty, 1970). 
However, for the following reasons we must be cautious in interpreting the abnormally high $\Delta^{14} \mathrm{C}$ as due to ${ }^{14} \mathrm{C}$ production by solar flare protons: 1) the $\Delta^{14} \mathrm{C}$ in the 1944 ring is at the same level as that in the 1942 ring; it does not show a gradual decay as it should; 2) the Washington State sample of Stuiver and Quay (1980) does not show any sign of $\Delta{ }^{14} \mathrm{C}$ increase. Thus, further work is needed to resolve the mystery.

\section{ACKNOWLEDGMENTS}

M L Parker, University of British Columbia, supplied us with the two sections of dendrochronologically calibrated white spruce which made this study possible. We are grateful to the Department of History, Peking University, and the Department of Physics, Nanjing University for their support. Special thanks from two of us (CYF \& KMD) go to Shi Shi-Yuan for his interest and guidance. The contribution of $\mathrm{Ma} \mathrm{Li}$ and Wang Bai-Zhen in processing the specimens was invaluable. This project is partially supported by Subcontract R 277664 from the University of Maryland.

\section{REFERENCES}

Baxter, M S and Farmer, J G, 1973, Radiocarbon: Short term variations: Earth Planetary Sci Letters, v 20, p 295-299.

Burchuladze, A A, Pagava, S V, Povinec, P, Togonidze, G I \& Usacev, S, 1980, Radiocarbon variations with the 11 -year solar cycle during the last century: Nature, v 287, p 320-322.

Damon, P E, Long, A \& Wallick, E I, 1973, On the magnitude of the 11-year radiocarbon cycle: Earth Planetary Sci Letters, v 20, p 300-306.

Dai, K M and Fan, C Y, 1986 , Bomb-produced ${ }^{14} \mathrm{C}$ content in tree rings grown at different latitudes, in Stuiver, $\mathrm{M}$ and $\mathrm{Kra}$, R S eds, Internatl ${ }^{14} \mathrm{C}$ conf, 12 th, Proc: Radiocarbon, this issue.

Fairhall, A W and Young, J A, 1970, Radiocarbon in the environment: Advances in chemistry series, no. 93, Radionuclides in the environment, p 401-418.

Fan, C Y, Chen, T M, Yun, S X and Dai, K M, 1983, Radiocarbon activity variation in dated tree rings grown in Mackenzie Delta, in Stuiver, $\mathrm{M}$ and $\mathrm{Kra}, \mathrm{R} \mathrm{S}$, eds, Internatl ${ }^{14} \mathrm{C}$ conf, $1 \mathrm{lth}$, Proc: Radiocarbon, v 25, no 2, p 205-212.

Forbush, S E, 1946, Three unusual cosmic-ray increases possibly due to charged particles from the sun: Physical Rev, v 7(), p 771-772.

Lingenfelter, R E and Ramaty, R, 1970, Astrophysical and geophysical variations in C14 production, in Olsson, I U, ed, Radiocarbon variations and absolute chronology: New York, John Wiley \& Sons, p 513-537.

Stuiver, $\mathrm{M}$ and Quay, P D, 1980, Changes in atmospheric carbon-14 attributed to a variable sun: Science, v 207, p 11-19.

Povinec, $\mathrm{P}, 1983$, Comparison of data on $\Delta^{14} \mathrm{C}$ variations with the $11-\mathrm{yr}$ solar cycle as obtained by different groups, in Stuiver, $\mathrm{M}$ and $\mathrm{Kra}, \mathrm{R} \mathrm{S}$, eds, Internatl ${ }^{14} \mathrm{C}$ conf, $1 \mathrm{lth}$, Proc: Radiocarbon v 25, no. 2, p 259-266.

Suess, H E, 1965, Secular variations of the cosmic ray produced carbon- 14 in the atmosphere and their interpretations: Jour Geophys Research, v 70, p 5937-5952.

Tans, P P, DeJong, A F and Mook, W G, 1979, Natural atmospheric ${ }^{14} \mathrm{C}$ variation and the Suess effect: Nature, v 280, p 826-828. 